\title{
Multi-Directional Forging and Warm Extrusion of AZ80Mg Alloys
}

\author{
Hiromi Miura $^{1}$, Keiichiro Minami ${ }^{1}$, Masakazu Kobayashi ${ }^{1}$ and Chihiro Watanabe ${ }^{2}$ \\ ${ }^{1}$ Department of Mechanical Engineering, Toyohashi University of Technology, Toyohashi 441-8580, Japan \\ ${ }^{2}$ Institue of Science and Engineering, Kanazawa University, Kanazawa 920-1192, Japan
}

A commercial hot-extruded AZ80Mg alloy was multi-directionally forged (MDFed) to a cumulative strain of $\Sigma \Delta \varepsilon=5.6$ at maximum under decreasing temperature conditions from $623 \mathrm{~K}$ down to $433 \mathrm{~K}$ at an initial strain rate of $3.0 \times 10^{-3} \mathrm{~s}^{-1}$. In addition to the above MDFing method, a simplified MDFing method, i.e., MDFing under two-step decreasing temperature conditions, was proposed and applied. These MDFing led to homogeneous grain refinements to have average grain sizes down to $0.6 \mu \mathrm{m}$. The MDFed Mg alloys were further extruded to form plates and tubes at temperatures between $453 \mathrm{~K}$ and $523 \mathrm{~K}$ at various initial strain rates from $3.0 \times 10^{-4} \mathrm{~s}^{-1}$ to $1.0 \times 10^{-2} \mathrm{~s}^{-1}$. Extrusions of the MDFed AZ80Mg alloys were successfully carried out even at such relatively low temperatures. Under some conditions, the strain-rate sensitivity of the flow stress exceeded 0.3, which suggested occurrence of superplastic deformation. By the above warm extrusion employing superplasticity accompanied by work hardening, high-strength AZ80Mg alloy tubes with tensile strength over $400 \mathrm{MPa}$ could be successfully fabricated. [doi:10.2320/matertrans.MT-M2020360]

(Received December 1, 2020; Accepted February 9, 2021; Published March 12, 2021)

Keywords: ultrafine grain, dynamic recrystallization, multi-directional forging, magnesium, extrusion, mechanical properties

\section{Introduction}

$\mathrm{Mg}$ alloys are one of the most light-weight metallic materials, which can be substitutions for Al alloys. However, further strengthening and improvement of plastic deformability are demanded to be employed as structural materials. For these purposes, numerous number of studies have been carried out. To overcome the poor deformability at ambient temperature of $\mathrm{Mg}$ alloys, they are plastically deformed essentially at elevated temperatures employing mechanisms of dynamic recrystallization (DRX) and dynamic recovery in addition to increment of the activated slip systems. ${ }^{1-5)}$ The deformation at elevated temperatures, hence, enables large plastic deformation to achieve desirable shapes. Nevertheless, it fatally derives softening and, therefore, decrease in strength at room temperature. ${ }^{5,6}$ The softening is caused by the drop of dislocation density due to DRX and dynamic recovery. ${ }^{1,3,5)}$ From the point of view of strengthening of $\mathrm{Mg}$ alloys, therefore, plastic forming at lower temperature is desirable.

It is known that, under certain conditions of low strain rate and elevated temperature, grain-boundary sliding (GBS) acts as one of the main mechanisms for the plastic deformation of ultrafine-grained (UFGed) $\mathrm{Mg}$ alloys. ${ }^{5,6}$ When GBS dominantly controls the plastic deformation, superplasticity can occur. This phenomenon is known to drastically facilitate large plastic deformation. While the researches on superplasticity in aluminum alloys have been statistically carried out, much less in Mg alloys. Recently, Miura et al. have examined superplastic behavior in UFGed AZ61Mg alloys with average grain sizes finer than $1 \mu \mathrm{m}$ and reported extraordinarily large ductility of $681 \%$ at warm temperature range of $423 \mathrm{~K}^{5}{ }^{5}$ Grain coarsening during superplastic deformation, which appears at conditions of low strain rate and high temperature, induces loss of ductility and softening. ${ }^{5,7)}$ At $423 \mathrm{~K}$, however, grain coarsening and dynamic recovery as well as DRX in the UFGed Mg alloys could be satisfactorily suppressed.5) Such large ductility by a mechanism of superplasticity indicates possibility of complex-shape forming of $\mathrm{Mg}$ alloys. Superplasticity in $\mathrm{Al}$ alloys have been practically used for the industrial mass productions. ${ }^{8)}$ Lin and Huang have reported high-strain-rate and low-temperature superplasticity of a fine-grained AZ31Mg alloy. ${ }^{9}$ Miura et al. have demonstrated efficiency of superplasticity for the plastic forming of UFGed AZ80Mg alloy. ${ }^{10)}$ As far as the authors know, however, there are a quite few researches on extrusion of UFGed Mg alloys employing a mechanism of superplastic deformation for complex-shape forming.

In the present study, warm extrusion of a UFGed AZ80Mg alloy was attempted to attain thin tubes without spoiling specific high strengths of the UFGed ones fabricated by means of multi-directional forging (MDFing). For the first step of warm extrusion, plates were extruded under various conditions, and then, the selected conditions were applied for the thin tube forming. The extrusion at warm temperature range was to avoid grain coarsening and softening. ${ }^{5,8,9)}$ And the changes in the microstructure and mechanical properties of the warm-extruded plates and tubes were investigated.

\section{Experimental}

\subsection{MDFing of the coarse-grained AZ80Mg alloy}

A commercial hot-extruded AZ80Mg alloy with an initial grain size of $19.3 \mu \mathrm{m}$ was cut into rectangular-shaped samples with dimensions of $15.0 \times 22.2 \times 33.3 \mathrm{~mm}^{3}$. The chemical composition is shown in Table 1 . They were heated to the MDFing temperature in a furnace for $180 \mathrm{~s}$ in advance and, then, MDFed on an Amsler-type universal mechanical testing machine under decreasing temperature conditions from $623 \mathrm{~K}$ down to $433 \mathrm{~K}$ at an initial strain rate of $3.0 \times 10^{-3} \mathrm{~s}^{-1}$. BN powder was employed as a lubricant. During MDFing, the forging axis was changed by 90 degrees from pass to pass. ${ }^{5,6}$ Pass strains of $\Delta \varepsilon=0.8$ were employed. The forging temperature, $623 \mathrm{~K}, 593 \mathrm{~K}, 543 \mathrm{~K}$, $513 \mathrm{~K}, 483 \mathrm{~K}, 453 \mathrm{~K}, 433 \mathrm{~K}$ at each forging pass, was chosen referring the reports by Miura et al. ${ }^{6,10)}$ The processing conditions are briefly illustrated by solid lines in Fig. 1. MDFing was carried out up to a cumulative strain of $\Sigma \Delta \varepsilon=5.6$ at maximum, i.e., 7 passes of forging. The first forging axis was set parallel to the hot extrusion direction. 
Table 1 Chemical composition of the hot-extruded AZ80Mg alloy in mass $\%$.

\begin{tabular}{|c|c|c|c|c|c|c|c|}
\hline $\mathrm{Al}$ & $\mathrm{Zn}$ & $\mathrm{Mn}$ & $\mathrm{Cu}$ & $\mathrm{Si}$ & $\mathrm{Fe}$ & $\mathrm{Ni}$ & $\mathrm{Mg}$ \\
\hline 8.4 & 0.60 & 0.32 & 0.002 & 0.024 & 0.005 & $<0.002$ & Bal. \\
\hline
\end{tabular}

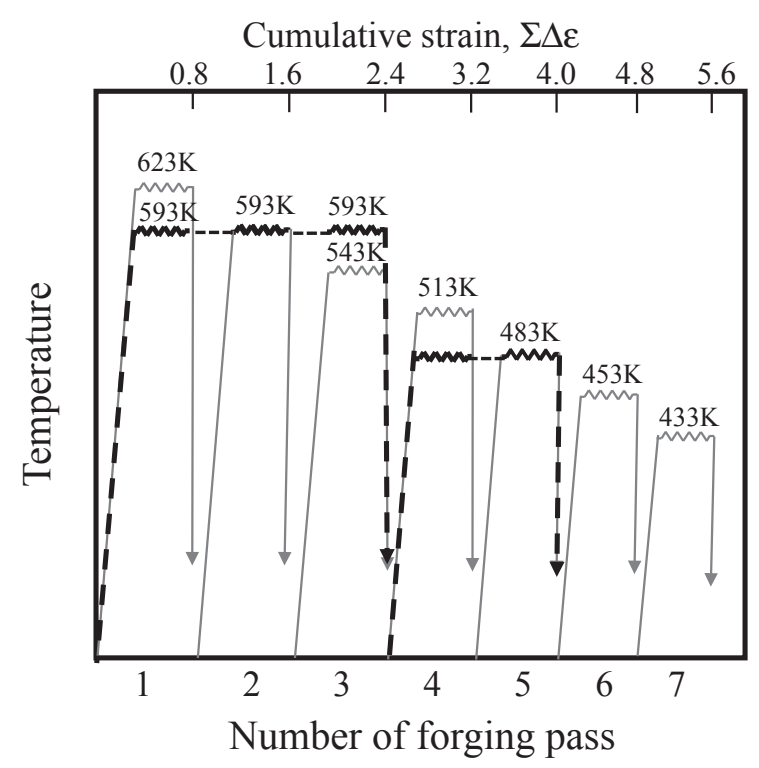

Fig. 1 Schematic diagram of the processes employing multi-directional forging under the conventional decreasing temperature conditions (solid lines) and the simplified two-step decreasing temperature conditions (broken lines). The latter can drastically reduce necessary procedures and the processing time down. Arrows indicate water quenching. Water quenching was carried out within $10 \mathrm{~s}$ to avoid microstructural changes.
This is because a sharp (0001) texture was developed on the surface parallel to the hot extrusion axis of the initial sample (see Fig. 2(a)). After each pass of forging, the samples were water quenched within $10 \mathrm{~s}$ in order to avoid microstructural changes.

Because the MDFing under decreasing temperature conditions is rather complicated process, another new process of MDFing under two-step decreasing temperature conditions is proposed for the simplification of the conventional MDFing process and actually applied; three passes of MDFing up to $\Sigma \Delta \varepsilon=2.4$ at $593 \mathrm{~K}$ and then the followed by two passes at $483 \mathrm{~K}$, i.e., MDFing cumulative strain of $\Sigma \Delta \varepsilon=4.0$ in total (see broken lines in Fig. 1). The forging temperature and the cumulative strain at each step in the modified MDFing process were decided to avoid cracking and to attain homogeneous microstructure. In this way, AZ80Mg alloys with various average grain sizes from $0.6 \mu \mathrm{m}$ to $19.3 \mu \mathrm{m}$ could be prepared.

\subsection{Extrusion of MDFed AZ80Mg alloys}

Subsequently, BN powder was again smeared on the planes of the rectangular-shaped samples as a lubricant. While samples were heated in advance at extrusion

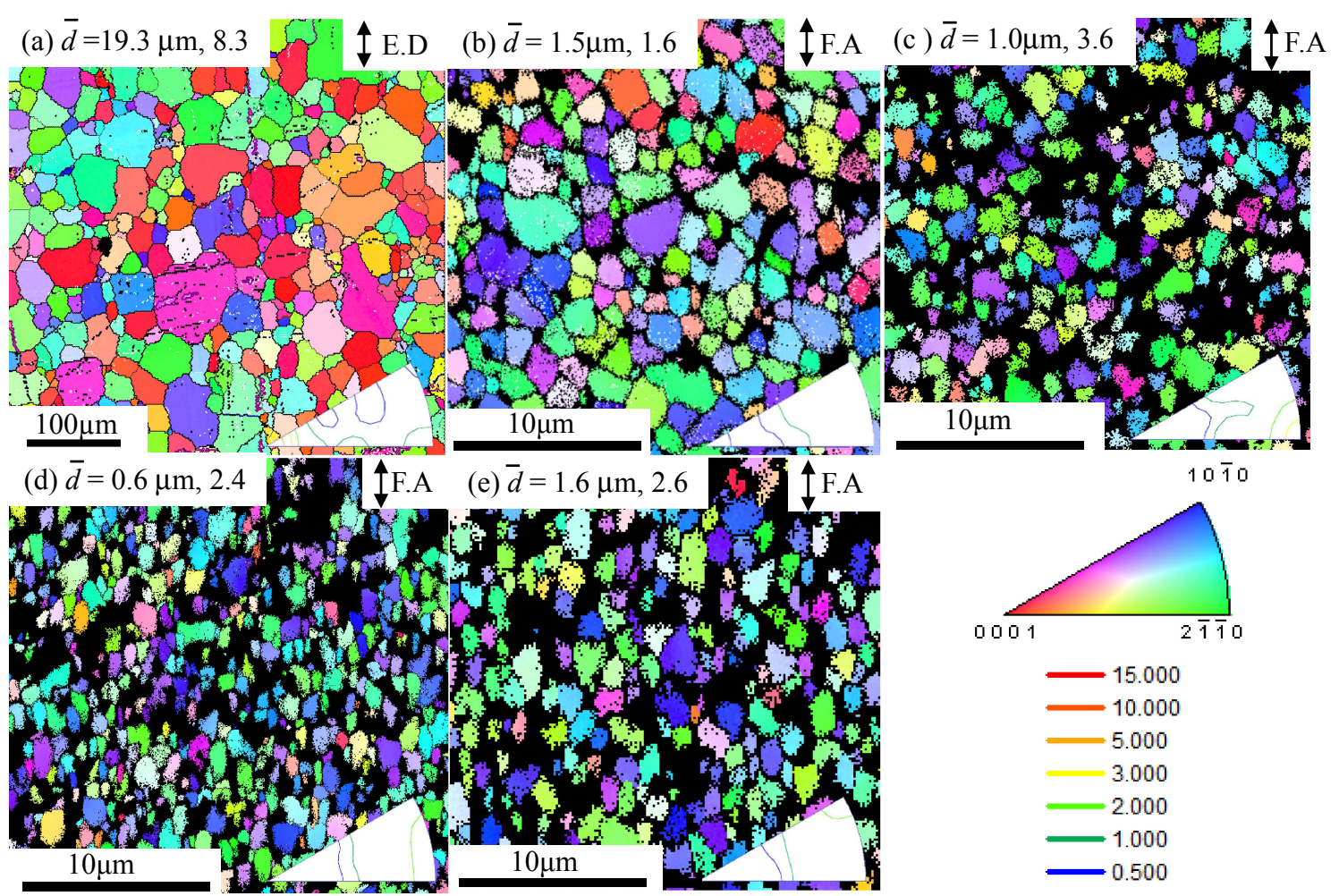

Fig. 2 Change in the microstructure during MDFing under decreasing temperature conditions; (a) as-hot extruded, and MDFed to (b) $\Sigma \Delta \varepsilon=3.2$, (c) $\Sigma \Delta \varepsilon=4.0$, (d) $\Sigma \Delta \varepsilon=5.6$. (e) is the microstructure evolved by MDFing under two-step decreasing temperature conditions to $\Sigma \Delta \varepsilon=4.0$. Average grain size and the maximum intensity of texture as well as the inverse pole figures are indicated. Please note that almost identical microstructures, (c) and (e), were developed at the same cumulative strain of $\Sigma \Delta \varepsilon=4.0$ even by the different MDFing processes. 
temperature for $180 \mathrm{~s}$ in a furnace, microstructural changes did not occur. The MDFed samples were set at the center of the heated dies to avoid contact of the $\mathrm{Mg}$ samples with the die walls at the initial stage of extrusion and, then, extruded to plates and tubes vertical downward on an Amsler-type universal mechanical testing machine equipped with dies, ram and a mandrel with a diameter of $8.0 \mathrm{~mm}$. Extrusion was carried out at temperatures between $453 \mathrm{~K}$ and $523 \mathrm{~K}$ at initial ram strain rates from $3.0 \times 10^{-4} \mathrm{~s}^{-1}$ to $1.0 \times 10^{-2} \mathrm{~s}^{-1}$. Extrusion direction was normal to the final forging axis of MDFing. In this way, plates with a cross section of $22.2 \times 4.0 \mathrm{~mm}^{2}$ and tubes with the diameter and thickness of $10 \mathrm{~mm}$ and $1.0 \mathrm{~mm}$ were extruded. The extrusion ratio was about 4.0 for plates and 10 for tubes respectively. The extrusion temperatures were much lower than those where extensive DRX took place. ${ }^{3-6)}$ Warm extrusion to thin tubes was carried out under selected conditions attained from those of plates because of the much larger extrusion ratio and higher flow stress.

\subsection{Microstructural observation and mechanical tests}

The evolved microstructure before and after extrusion was observed using the electron-back-scattering-diffraction (EBSD) method after mechanical and electrolytic polishing. The EBSD observations were carried out on the planes parallel to the final forging axis of MDFing before extrusion, on the wider planes of the extruded plates and on the longitudinal surface of the tubes. The observations were performed at an accelerating voltage of $20 \mathrm{kV}$ with a beam step of $0.1 \mu \mathrm{m}$. The mechanical properties were investigated by tensile tests on an Instron-type universal mechanical testing machine at an initial strain rate of $1.0 \times 10^{-3} \mathrm{~s}^{-1}$. The gauge dimensions of the tensile samples were $2.4 \times 5.0 \times$ $0.7 \mathrm{~mm}^{3}$, while the gauge part of the samples cut from tube was curved as it was. The loading directions were either normal to the final forging axis of MDFing or parallel to the extrusion axis. The change in the hardness was examined by micro-Vickers hardness tester with a load of $2.94 \mathrm{~N}$.

\section{Results and Discussion}

\subsection{Evolved microstructure by MDFing}

The microstructure evolved by MDFing is displayed in Fig. 2. It can be seen in Fig. 2 that the coarse initial grains in the hot-extruded sample (Fig. 2(a)) were gradually fragmented to equi-axed homogeneous UFGs. Completely homogeneous microstructures were developed irrespective of position of the samples because of extensive occurrence of DRX. The achieved grain sizes by the MDFing under decreasing temperature conditions were $1.5 \mu \mathrm{m}$ at $\Sigma \Delta \varepsilon=3.2$ (Fig. 2(b)), $1.0 \mu \mathrm{m}$ at $\Sigma \Delta \varepsilon=4.0$ (Fig. 2(c)) and $0.6 \mu \mathrm{m}$ at $\Sigma \Delta \varepsilon=5.6$ (Fig. 2(d)), respectively Such warm temperature forging as low as $433 \mathrm{~K}$ without any cracking was enabled by the effect of GBS as well as DRX. ${ }^{5,6,10)}$ GBS takes place even at room temperature ${ }^{11)}$ and it becomes more substantial with decreasing grain size and with increasing temperature. ${ }^{5,12)}$ The changes in the grain size and the hardness with increasing cumulative strain were summarized in Fig. 3. The grain size rapidly decreases at the lower cumulative strain region. However, at higher cumulative strain region,

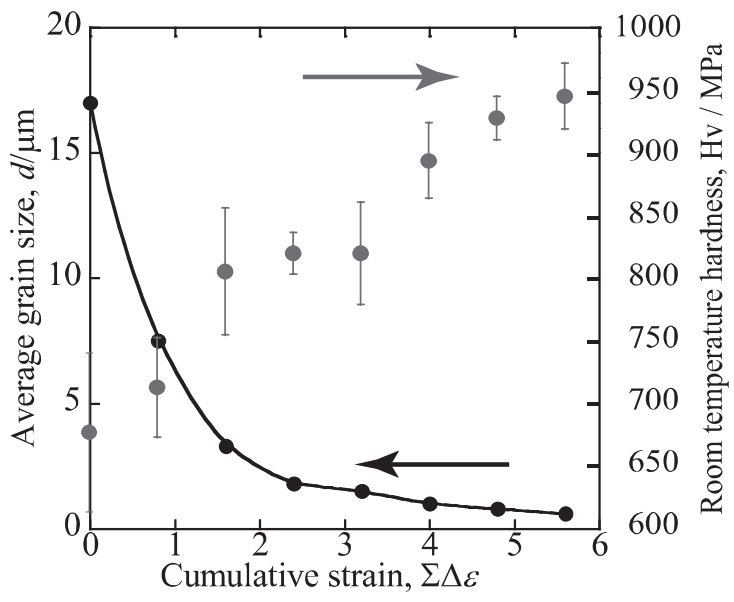

Fig. 3 Changes in the average grain size and the micro-Vickers hardness with increasing cumulative strain during MDFing under decreasing temperature conditions. The average values of hardness were obtained from 8 data after exclusion of the maximum and minimum values among 10 measurements.

the change becomes gradual and quite slowly. Miura et al. reported that the change in the mechanisms of grain fragmentation during MDFing of $\mathrm{Mg}$ alloys under decreasing temperature conditions occurred from mechanical twinning and kinking in addition to DRX at lower cumulative strain region and, then, mainly to DRX at higher cumulative strain region. ${ }^{5,6,12)}$ The transition of the dominant mechanisms of grain refinement was affected by changes in grain size, flow stress and forging temperature, which will be discussed later. It is interesting to compare Figs. 2(c) and (e) that almost identical microstructures and grain size were attained, although different MDFing processes were applied. This must be because that achieved grain size by DRX is a function of temperature and strain rate. ${ }^{13)}$ The results in Fig. 2 suggests that the MDFing method can be simplified significantly by the newly proposed process of MDFing under two-step decreasing temperature conditions. On the other hand, the hardness in Fig. 3 looks raised monotonically as the increase in the cumulative strain. This increment in the hardness with increasing cumulative strain was induced not only by the grain refinement but also by the increase in the dislocation density. That is, decrease in the forging temperature at higher cumulative strain region derived delay of recovery and, therefore, increase in the dislocation density to cause larger work hardening.

When compare the texture during MDFing in Fig. 2, it is interesting to know that the basal texture developed in the ashot extruded sample was drastically weakened by MDFing. This is due to change of the forging direction during MDFing, and DRX nucleation at twins and kinks which possess rather large misorientations with their mother grains. ${ }^{5,6,12)}$ Even while MDFed to high cumulative strain regions, the orientation was not completely randomized. This is because samples were forged to a pass strain of $\Delta \varepsilon=0.8$ at each pass and, therefore, texture is fatally developed in greater or less degree. It is well-known that the evolution of such sharp basal texture spoils plastic formability of $\mathrm{Mg}$ alloys especially at ambient temperature owing to lack of activated slip systems. ${ }^{14,15)}$ The weakened basal texture after 

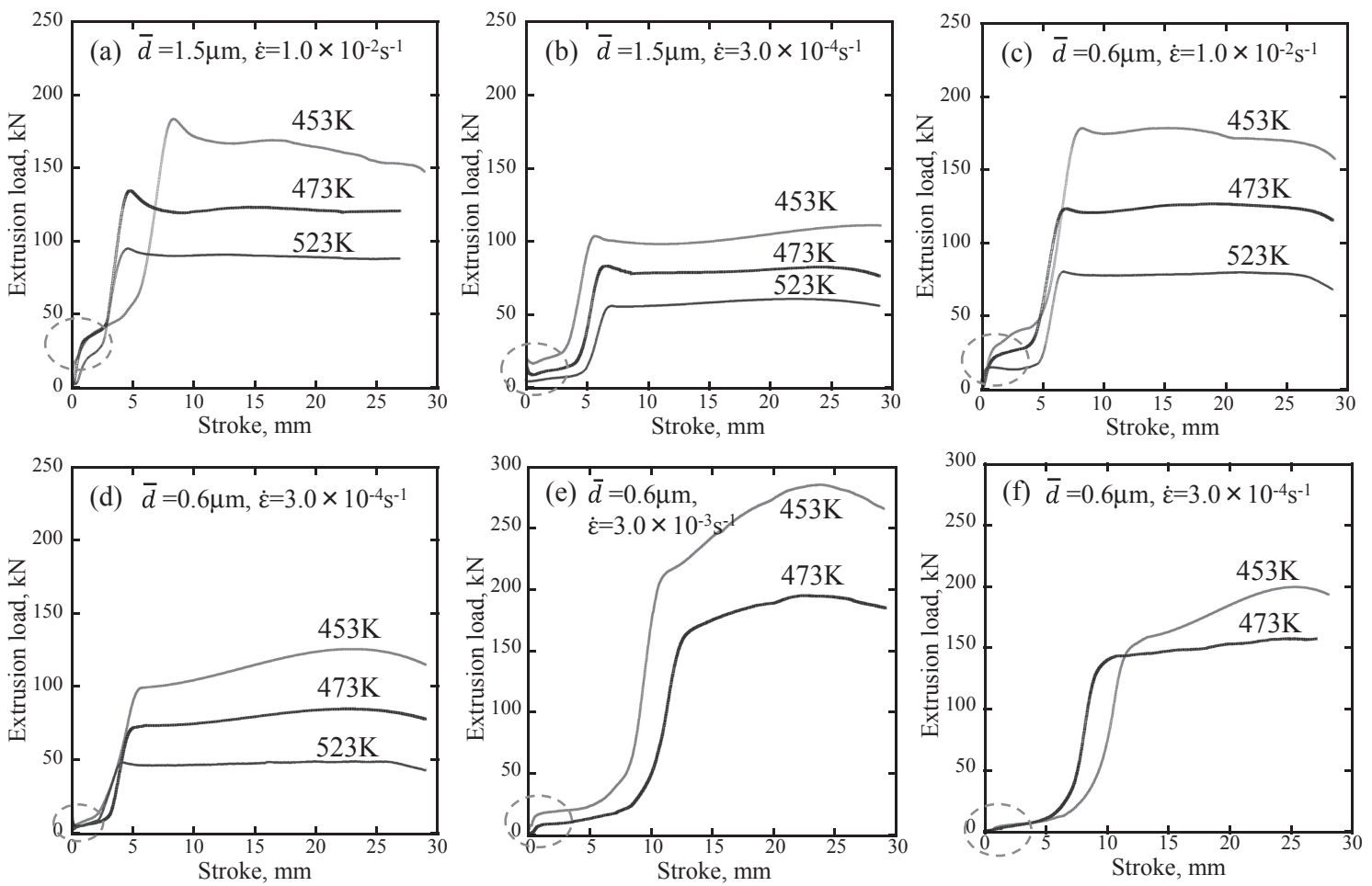

Fig. 4 Change in extrusion load of the MDFed AZ80Mg alloys to plates depending on ram strain rate, temperature and cumulative strain of MDFing in advance; $\Sigma \Delta \varepsilon=3.2$ for (a), (b) and $\Sigma \Delta \varepsilon=5.6$ for (c), (d), respectively. The average grain size attained by MDFing under decreasing temperature conditions to $\Sigma \Delta \varepsilon=3.2$ and $\Sigma \Delta \varepsilon=5.6$ was $1.5 \mu \mathrm{m}$ and $0.6 \mu \mathrm{m}$. (e) and (f) are those for tubes from the MDFed ones under decreasing temperature conditions to $\Sigma \Delta \varepsilon=5.6$ in advance. The yielding points were roughly indicated by circles.

MDFing implies the additional superior plastic deformability in addition to the effect of GBS. ${ }^{5,6,12)}$

\subsection{Warm extrusion of the MDFed AZ80Mg alloys}

The samples MDFed under decreasing temperature conditions to $\Sigma \Delta \varepsilon=3.2$ and $\Sigma \Delta \varepsilon=5.6$, which were composed of homogeneous microstructures with average grain sizes of $1.5 \mu \mathrm{m}$ and $0.6 \mu \mathrm{m}$ (see Figs. 2(b), (d)), were warm extruded at some temperatures between $453 \mathrm{~K}$ and $523 \mathrm{~K}$ where superplastic behavior of the UFGed-Mg alloys has been reported. ${ }^{5,6,10)}$ The samples produced by MDFing under two-step decreasing temperature conditions to have homogeneous microstructure with an average grain size of $1.6 \mu \mathrm{m}$ (Fig. 2(e)) were extruded in the same way. Although extruded at much lower temperatures than those for the conventional forming, ${ }^{1-4)}$ the warm extrusion of the $\mathrm{Mg}$ alloys was successfully carried out when grain size was fine enough. Cracking tended to appear when grain size was large and extruded at lower temperatures and at higher ram speeds. The as hot-extruded initial samples composed of coarse grains were severely cracked almost in all the present extrusion conditions. The examples of the measured extrusion load as a function of the ram stroke during extrusion are exhibited in Fig. 4. After showing unclear yielding, the loads first gradually and then quickly raised with increasing ram stroke. The quick increase in the loads is owing to the contact of the $\mathrm{Mg}$ alloy samples with the die wall. And it almost saturated by the full contact to onset extrusion of plates or tubes. It is evident in Fig. 4 that the loads increased as the increase in ram speed and decrease in temperature. It should be noted that the temperature and strain-rate sensitivities of the flow stress appear more significant in the samples MDFed to $\Sigma \Delta \varepsilon=5.6$ than those of MDFed to $\Sigma \Delta \varepsilon=3.2$. The same tendencies were observed during extrusion of the samples prepared by MDFing under two-step decreasing temperature conditions, while the former result is not included in Fig. 4. When compare the extrusion loads for the plates and tubes, it for the tubes (Figs. 4(e) and (f)) is much higher than those for plates. This is due to the much larger extrusion ratio for tubing than that for the plate extrusion.

It is known that occurrence of GBS strongly affects the deformation behavior at elevated temperatures and the effects becomes more noteworthy under conditions of lower strain rate and higher temperature. ${ }^{5,6,11)}$ When the value of strainrate sensitivity of flow stress $m$ exceeds 0.3 , it is recognized that deformation is dominated by GBS and, therefore, superplasticity is taking place, ${ }^{5,8)}$ where $m$ is expressed by $m=\partial \ln \sigma / \partial \ln \dot{\varepsilon}$ with strain rate $\dot{\varepsilon}$ and flow stress $\sigma$. In the present study, genuine steady-state flow stress did not appear in all the extrusions because of the interference between the MDFed samples and the die wall irrespective of the ram stroke. For convenience, hence, the $m$ value was estimated using the yield stress, derived by the $0.2 \%$ off set method, where contact between the samples and the die wall did not take place. GBS is known to extensively take place before macroscopic yielding to cause localized plastic deformation during hot deformation. ${ }^{16)}$ GBS and, therefore, the plastic deformation before the yielding in the UFGed AZ80Mg alloys must be more extensive at elevated temperatures. The 

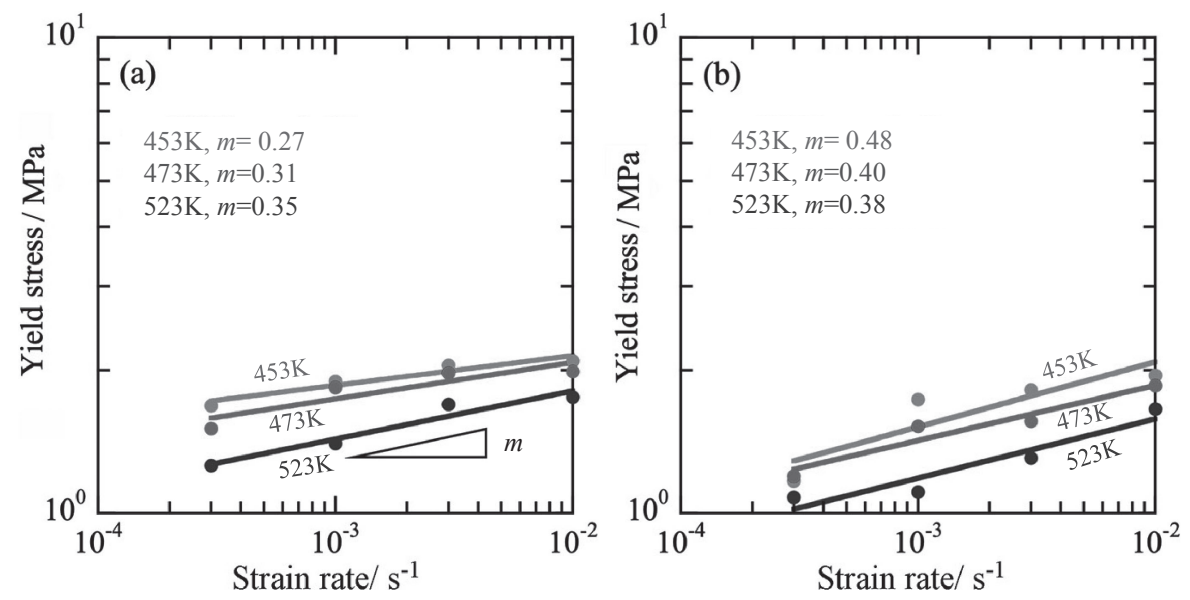

Fig. 5 Evaluation of strain-rate sensitivity $m$ during extrusion of MDFed AZ80Mg alloys to plates; AZ80Mg samples (a) MDFed under decreasing temperature conditions to $\Sigma \Delta \varepsilon=3.2$ and (b) $\Sigma \Delta \varepsilon=5.6$. The average grain sizes attained by MDFing to $\Sigma \Delta \varepsilon=3.2$ and $\Sigma \Delta \varepsilon=5.6$ were $1.5 \mu \mathrm{m}$ and $0.6 \mu \mathrm{m}$.

results shown in Fig. 5 clearly demonstrates large $m$ values above 0.3 at the temperatures of $473 \mathrm{~K}$ or over. Especially for the sample with an average grain size of $0.6 \mu \mathrm{m}$ exhibits much larger $m$ values than that of $1.5 \mu \mathrm{m}$ and, still more, the $m$ value exceeded 0.3 at all the present testing conditions. This should strongly suggest more dominant role of GBS in the UFGed samples. ${ }^{9)}$ The $m$ values of the samples fabricated by MDFing under two-step decreasing temperature conditions were 0.32 at $453 \mathrm{~K}$ and 0.42 at $473 \mathrm{~K}$. These analyses confirmed extensive occurrence of GBS and, therefore, lowtemperature superplasticity enabled the warm extrusion of the UFGed AZ80Mg alloys. Lin and Huang reported superplasticity of AZ31Mg alloys with average grain sizes from 1 to $4 \mu \mathrm{m}$ at the temperatures from $473 \mathrm{~K}$ to $\left.623 \mathrm{~K}{ }^{9}{ }^{9}\right)$ Mabuchi et al. showed superplasticity at $475 \mathrm{~K}$ of the AZ91Mg alloy processed by equal-channel-angular pressing. ${ }^{17)}$ The latters successfully demonstrated superplasticity of AZ91Mg alloy processed by equal-channel-angular pressing at further lower temperature of $423 \mathrm{~K}^{18)}$ Mehrabi et al. investigated superplastic behavior of MDFed $\mathrm{Mg}-\mathrm{Li}-$ $\mathrm{Zn}$ alloys between $498 \mathrm{~K}$ and $573 \mathrm{~K}$ and reported change in the $m$ value from 0.29 to 0.51 depending on grain size and testing conditions. ${ }^{19)}$ Still more, Miura et al. reported superplasticity even at $373 \mathrm{~K}$ of UFGed AZ61Mg alloys with an average grain size of $0.3 \mu \mathrm{m} .{ }^{5)}$ Consequently, the superplasticity of $\mathrm{Mg}$ alloys can occur at lower temperatures when grain size becomes approximately less than a few micrometers and it becomes easier with decreasing grain size. This is in good accordance with the results in the present study.

\subsection{Microstructural change by warm extrusion}

The evolved microstructure observed by means of EBSD as well as photographs of the warm-extruded samples are displayed in Figs. 6 and 7. It is distinct that the grain size was reduced after warm extrusion under conditions of higher ram speed and lower temperature. The average grain size of $1.5 \mu \mathrm{m}$ (Fig. 2(b)) was reduced down to $0.8 \mu \mathrm{m}$ by the extrusion to plates at $453 \mathrm{~K}$ at $1.0 \times 10^{-2} \mathrm{~s}^{-1}$ (Fig. 6(a)). This grain refinement would be caused by DRX and mechanical twinning. This will be discussed later.
In contrast, grain coarsening took place apparently when extruded at higher temperature and at lower ram speed. The extrusion at $523 \mathrm{~K}$ and at $3.0 \times 10^{-4} \mathrm{~s}^{-1}$ induced grain coarsening from $0.6 \mu \mathrm{m}$ to $2.3 \mu \mathrm{m}$ (Fig. 6(i)). Completely same tendency was observed also during extrusion to tubes (Fig. 7). Hence, microstructural change occurs sensitively depending on extruding conditions. It is also interesting to note that basal texture evolved regardless of the extrusion conditions. The intensity of basal texture after extrusion appeared slightly sharper in the samples MDFed to $\Sigma \Delta \varepsilon=$ 3.2 (Fig. 6) in advance than those MDFed to $\Sigma \Delta \varepsilon=5.6$ in advance. The evolution of basal texture suggests that extrusion is accompanied by plastic deformation by the basal slip even while superplasticity is the most dominant deformation mechanism. Nevertheless, the occurrence of superplasticity should effectively suppress a severe basal texture evolution. When examined the change in the hardness, it tended to increase by extrusion (Fig. 8) and became higher with decreasing extrusion temperature. While UFGed-AZ61Mg alloy prepared by MDFing exhibits agehardenability at $423 \mathrm{~K}$ and shows peaks at around $3 \times 10^{3} \mathrm{~s}$, the hardness increment was only $5 \%$ at maximum. ${ }^{12)}$ In the present study, the warm extrusion at $1.0 \times 10^{-2} \mathrm{~s}^{-1}$ was accomplished within $15 \mathrm{~min}\left(9 \times 10^{2} \mathrm{~s}\right)$ including the time for the sample heating. The observed increase in the hardness shown in Fig. 8 should be, therefore, caused mainly work hardening which occurred during low-temperature superplastic deformation.

Twins were frequently formed irrespective of grain size of the matrix almost in whole extruded samples (Fig. 6). This observation is in qualitative disagreement with the report by Barnett et al. that mechanical twinning becomes difficult when the grain size is reduced to less than $6 \mu \mathrm{m} .{ }^{20}$ ) This difference should be due to the applied flow stresses for the deformations. They could apply much lower flow stress for the hot torsion test due to extensive occurrence of dynamic recrystallization. On the other hand, no dynamic recrystallization took place during warm extrusion in the present study, therefore, flow stress became much higher. That is, even while grain size becomes finer, further twinning to induce grain subdivision can occur by large applied flow stress. ${ }^{21)}$ 

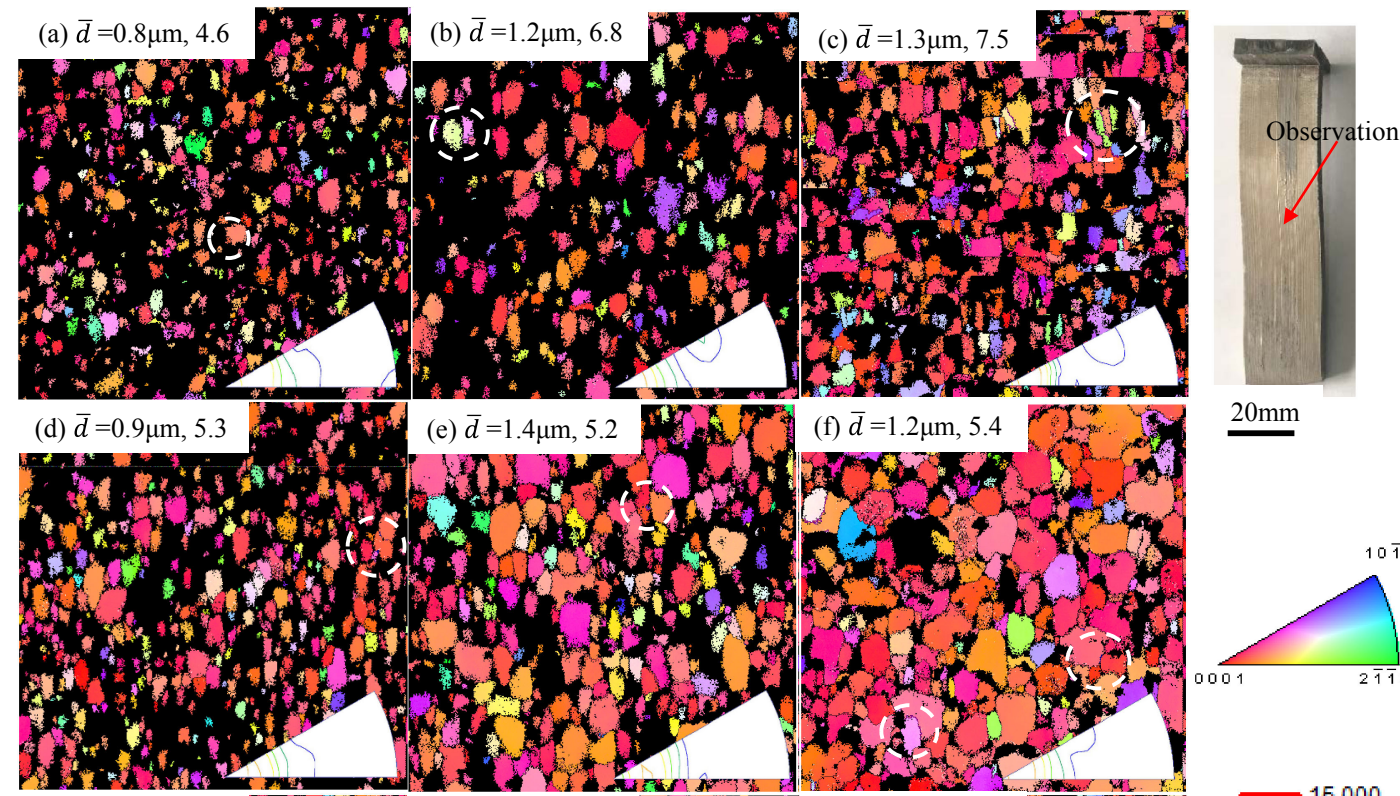

$20 \mathrm{~mm}$
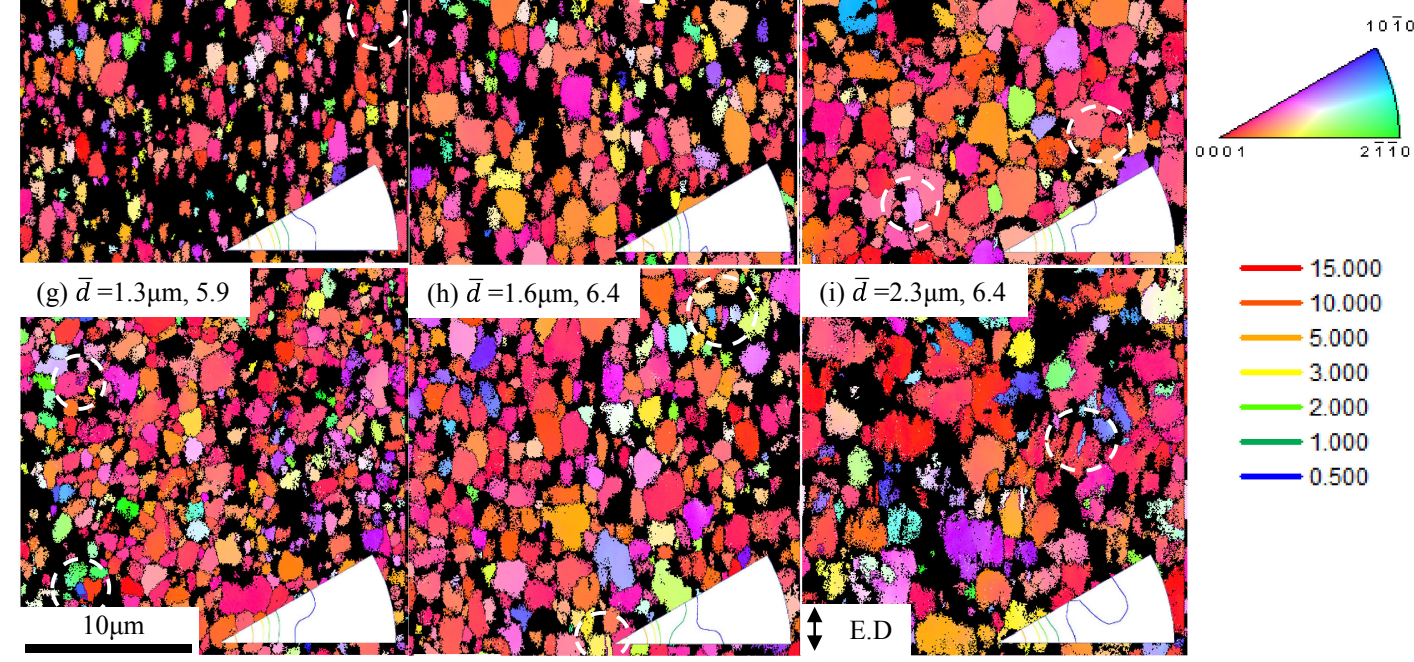

Fig. 6 Microstructural change by warm extrusion to plates of the MDFed AZ80Mg alloys under decreasing temperature conditions to $\Sigma \Delta \varepsilon=3.2$, (a), (b), (c), and to $\Sigma \Delta \varepsilon=5.6$, (d), (e), (f), (g), (h), (i). Extrusion was carried out for (a), (d), (g) at 453 K, (b), (e), (h) at $473 \mathrm{~K}$ and (c), (f), (i) at $523 \mathrm{~K}$. The ram strain rate was $1.0 \times 10^{-2} \mathrm{~s}^{-1}$ for (a), (b), (c), (d), (e), (f) and $3.0 \times 10^{-4} \mathrm{~s}^{-1}$ for (g), (h), (i). ED is the extruding direction. Average grain size and the maximum intensity of texture as well as the inverse pole figures The warm extruded plate sample is also displayed. Circles are samples of areas where mechanical twins were formed.

This effect induced more significant grain refinement under the conditions of lower temperature and higher ram strain rate where higher flow stress could be applied (Figs. 6, 7). The fraction of twin boundaries among the all grain boundaries included in the microstructures after warm extrusion was $6.1 \%$ at minimum and $23.3 \%$ at maximum. The majority of twins were of $\left(\begin{array}{llll}1 & 0 & -1 & 2\end{array}\right)$ tensile type. When much higher flow stress is applied for deformation, nanometer-sized compression twins are high densely formed to cause UFG evolution. ${ }^{21)}$ However, in the present study, much finer twins as (1 $11-2$ ll 1$),\left(\begin{array}{llll}1 & 1 & -2 & 2\end{array}\right)$ and $\left(\begin{array}{llll}1 & 0 & -1 & 1\end{array}\right)$ types could not be frequently detected because of the limited resolution of EBSD measurement. It is assumed, therefore, that the fraction of twins should be higher than shown above.

\subsection{Tensile behavior of the warm-extruded AZ80Mg alloys}

The warm-extruded AZ80Mg alloys were tensile tested at room temperature and the samples of flow curves are exhibited in Figs. 9 and 10, and the summarized results are listed in Tables 2, 3, 4, 5. The as-MDFed samples under decreasing temperature conditions to $\Sigma \Delta \varepsilon=3.2$ and $\Sigma \Delta \varepsilon=$ 5.6 show a good balance of mechanical properties (yield strengths of $256 \mathrm{MPa}$ and $322 \mathrm{MPa}$, UTS of $347 \mathrm{MPa}$ and $385 \mathrm{MPa}$, and same ductility of $16 \%$, respectively). It is interesting to recognize that the mechanical properties of the MDFed samples to $\Sigma \Delta \varepsilon=3.2$ under two-step decreasing temperature conditions (Table 4) look almost same with those of the as-MDFed ones under decreasing temperature conditions to $\Sigma \Delta \varepsilon=3.2$ (Table 2) and to $\Sigma \Delta \varepsilon=4.0$ (not shown here). The above comparisons of the mechanical properties as well as microstructures (Fig. 2) should prove equivalency of the fabricated UFGed AZ80Mg alloys through different MDFing processes. Those of the as-hot extruded initial samples are as follows; yield strength of $216 \mathrm{MPa}$, UTS of $350 \mathrm{MPa}$, and ductility of $18 \%$. Hence, the large improvement of the mechanical properties was definitely attained by MDFing to $\Sigma \Delta \varepsilon=5$.6. However, those by MDFing to $\Sigma \Delta \varepsilon=3.2$ were still insufficient. It is evident, therefore, UFGed structure with a grain size less than $1 \mu \mathrm{m}$ is required for the drastic improvement of mechanical properties of $\mathrm{Mg}$ alloys. ${ }^{5,6,12)}$

On the other hand, the mechanical properties were significantly more improved especially when extruded under conditions of lower temperature and higher ram speed. Yield strength over $350 \mathrm{MPa}$ and UTS over $380 \mathrm{MPa}$ without largely spoiling ductility could be achieved by warm extrusion to plates. In the same way, the plates fabricated through the MDFing to $\Sigma \Delta \varepsilon=4.0$ under two-step decreasing temperature conditions also show similar mechanical 


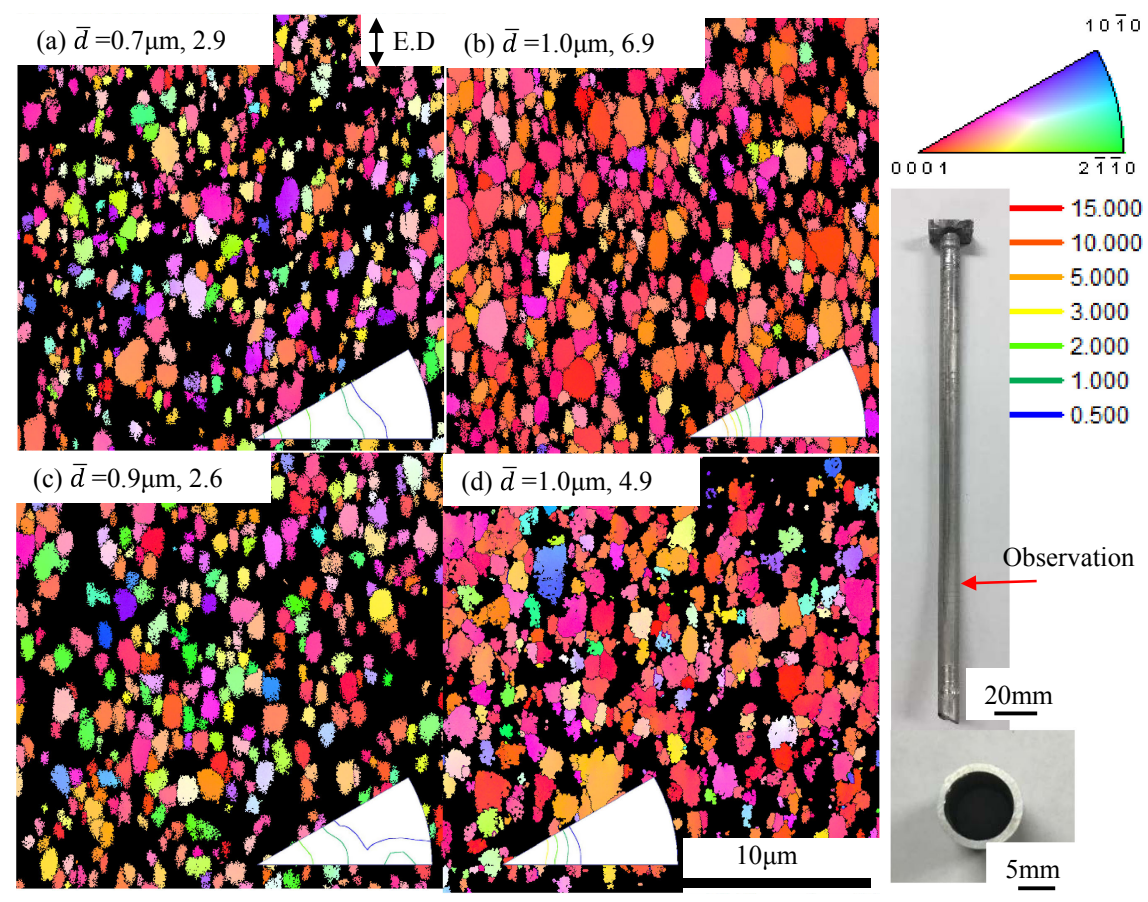

Fig. 7 Microstructural change by warm extrusion to tubes of the MDFed AZ80Mg alloys to SDe $=5.6$ under decreasing temperature conditions in advance. Extrusion was carried out at $453 \mathrm{~K}$ for (a) and (c), and at $473 \mathrm{~K}$ for (b) and (d). The ram strain rate was $3.0 \times 10^{-3} \mathrm{~s}^{-1}$ for (a) and (b), and $3.0 \times 10^{-4} \mathrm{~s}^{-1}$ for (c) and (d). ED is the extruding direction. The attained average grain size and the maximum intensity of texture as well as the inverse pole figures after extrusion are also shown. The photographs of the warm extruded tube are displayed.

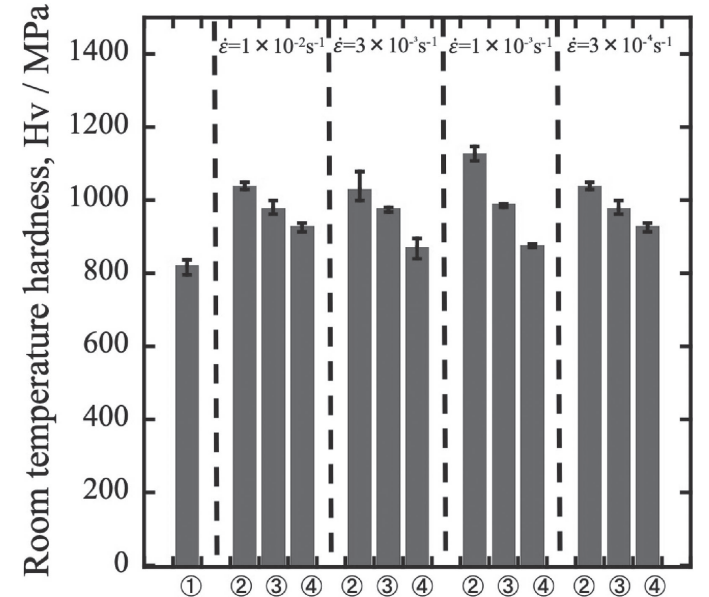

Fig. 8 Change in the hardness depending on temperature and strain rate of the warm extrusion of the MDFed AZ80Mg alloy to a cumulative strain of $\Sigma \Delta \varepsilon=3.2$; (1) as-MDFed, (2) MDFed to $\Sigma \Delta \varepsilon=3.2$ and then extruded at $453 \mathrm{~K}$, (3) MDFed and extruded at $473 \mathrm{~K}$, (4) MDFed and extruded at $523 \mathrm{~K}$, respectively. The ram strain rate is indicated at upper part.

properties (Table 4). These similar mechanical properties after warm extrusion to plates of all MDFed samples to $\Sigma \Delta \varepsilon=3.2$ and $\Sigma \Delta \varepsilon=5.6$ in advance (Tables 2, 3, 4) would be because of the identical microstructure and grain size developed by extrusion (Figs. 2 and 6). The warm-extruded tubes possess further superior tensile strengths over $400 \mathrm{MPa}$ (Table 5), while ductility was reduced almost to half. This should be because of much larger extrusion ratio to induce much higher flow stress during extrusion (Fig. 4) and, therefore, larger strain hardening took place.
The tensile strength of the hot-extruded $\mathrm{Mg}$ alloys is known to be lower compared with those of the Al alloys. One of the reasons is that the hot extrusion is normally carried out at quite high temperatures to overcome poor ductility and to employ DRX. ${ }^{1,3-5,9)}$ Therefore, various attempts to fabricate $\mathrm{Mg}$ alloys tubes have been carried out. Yoon et al. reported the yield and UTS of an AZ61Mg tube machined from a hotextruded billet to be approximately $160 \mathrm{MPa}$ and $320 \mathrm{MPa}^{22)}$ Huang et al. reported that tensile strength of the hot-extruded AZ31Mg alloy tubes at temperatures over $573 \mathrm{~K}$ was between $253 \mathrm{MPa}$ and $277 \mathrm{MPa}{ }^{23)}$ They also demonstrated its hydroforming and raised the strength to certain degree. The best one available is found in the data base in The Japan Magnesium Association; $350 \mathrm{MPa}$ of a ZK60A-F alloy tube. $^{24)}$ The present study, however, much higher tensile strength of $414 \mathrm{MPa}$ as well as notably high yield strength of $379 \mathrm{MPa}$ at best was achieved. This superior strength of the tube was induced by low-temperature superplasticity of UFGed-AZ80Mg alloy without grain coarsening but accompanied by work hardening. While the yield strength was drastically raised because of combined effects of work hardening, UFGed structure and sharp basal texture, ductility was conversely reduced. Nevertheless, it is concluded that a possibility to produce high-strengthened $\mathrm{Mg}$ alloy tube could be actually demonstrated.

\section{Conclusions}

Multi-directionally forged (MDFed) AZ80Mg alloys were extruded to plates and tubes at warm-temperature rage where extensive grain coarsening hardly took place. The yielded results are shown below. 

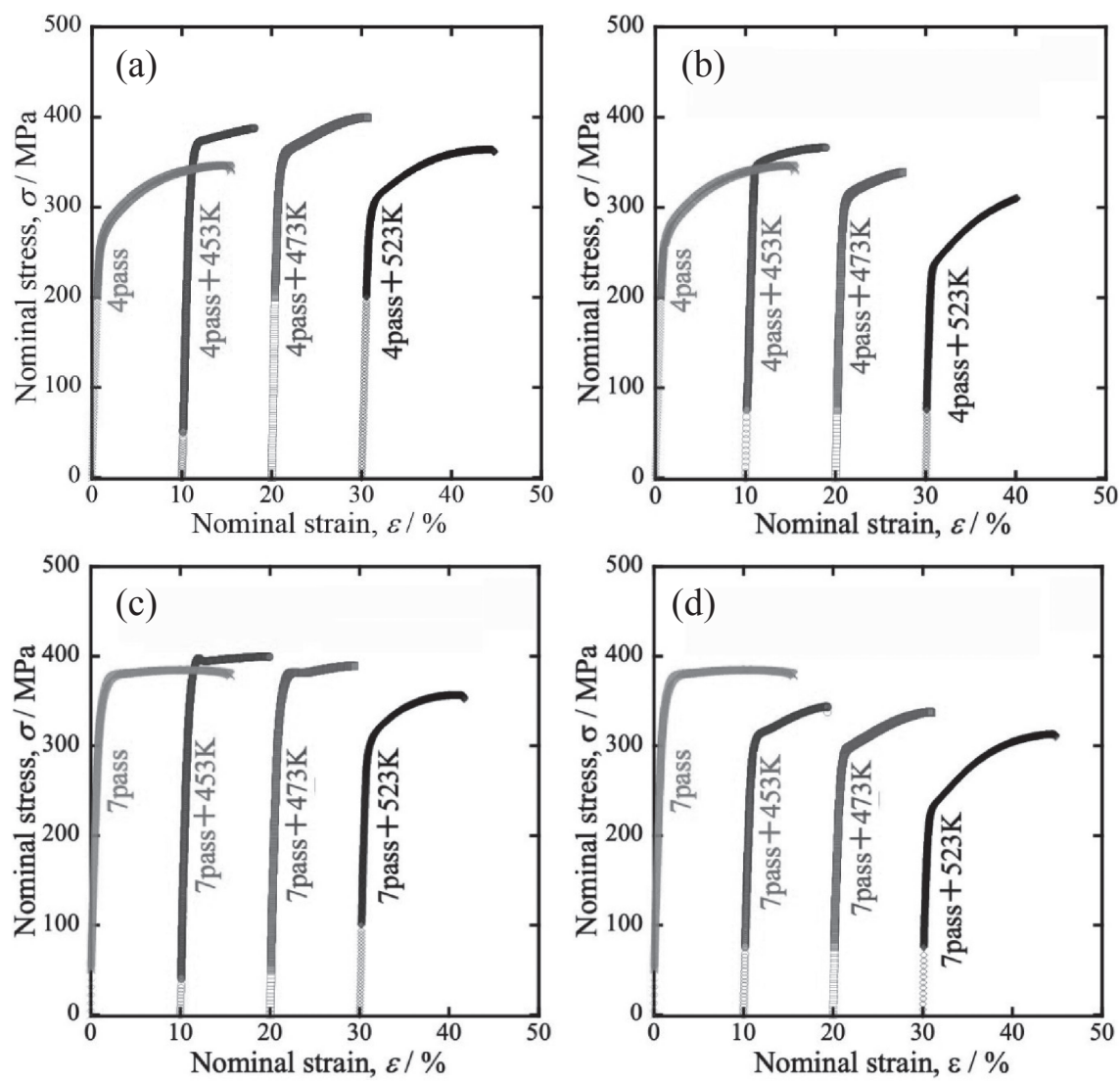

Fig. 9 Nominal stress vs. nominal strain curves attained by tensile tests of the warm extruded AZ80Mg alloy plates; (a) MDFed to $\Sigma \Delta \varepsilon=3.2$ under decreasing temperature conditions in advance and then extruded at a ram strain rate of $1.0 \times 10^{-2} \mathrm{~s}^{-1},(\mathrm{~b}) \mathrm{MDFed}$ to $\Sigma \Delta \varepsilon=3.2$ and extruded at a ram strain rate of $3.0 \times 10^{-4} \mathrm{~s}^{-1}$, (c) MDFed to $\Sigma \Delta \varepsilon=5.6$ and extruded at a ram strain rate of $3.0 \times 10^{-3} \mathrm{~s}^{-1}$, (d) MDFed to $\Sigma \Delta \varepsilon=6.4$ and extruded at $3.0 \times 10^{-4} \mathrm{~s}^{-1}$. The references of " 4 pass" and "7 pass" mean the samples asMDFed to $\Sigma \Delta \varepsilon=3.2$ and $\Sigma \Delta \varepsilon=5.6$, respectively. " 4 pass $+453 \mathrm{~K}$ " indicates the sample MDFed to $\Sigma \Delta \varepsilon=3.2$ in advance and then extruded at $453 \mathrm{~K}$

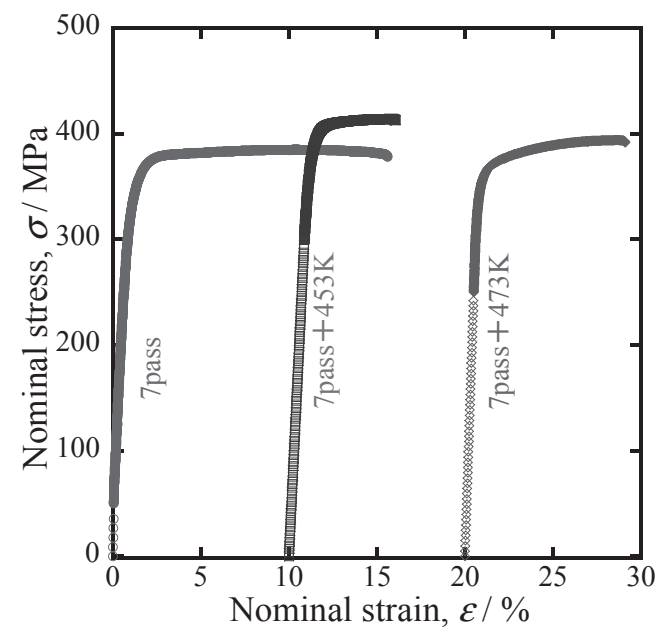

Fig. 10 Nominal stress vs. nominal strain curves attained by tensile tests of the warm extruded AZ80Mg alloy tubes. MDFed to $\Sigma \Delta \varepsilon=5.6$ under decreasing temperature conditions in advance and then extruded at a ram strain rate of $3.0 \times 10^{-3} \mathrm{~s}^{-1}$. The reference of " 7 pass $+453 \mathrm{~K}$ " indicates the sample MDFed to $\Sigma \Delta \varepsilon=5.6$ in advance and then extruded at $453 \mathrm{~K}$.

(1) Ultrafine-grained (UFGed) AZ80Mg alloys with various average grain sizes from $0.6 \mu \mathrm{m}$ to $19.3 \mu \mathrm{m}$ could be fabricated by MDFing. Two types of MDFing, a conventional MDFing under decreasing temperature conditions and newly proposed MDFing under twostep decreasing temperature conditions, could develop the almost identical microstructure and mechanical properties.

(2) Warm extrusion at $453 \mathrm{~K}$ of the UFGed AZ80Mg alloys to plates and tubes was successively accomplished. The large strain-rate sensitivity of the load stress over 0.3 during extrusion indicated occurrence of low-temperature superplasticity.

(3) The extrusionability tended to become better with decreasing grain size and ram strain rate and with increasing temperature. The increment in the strain-rate sensitivity with decreasing grain size suggested more prominent role of grain-boundary sliding during extrusion.

(4) By the above warm extrusion, AZ80Mg alloy plate with yield strengths over $350 \mathrm{MPa}$ and ultimate tensile strengths over $380 \mathrm{MPa}$ could be fabricated without spoiling ductility. Furthermore, the mechanical properties of the tube were more improved to show yield strength of $379 \mathrm{MPa}$ and ultimate tensile strength of $414 \mathrm{MPa}$ at best.

(5) The achieved high strengths were derived by the lowtemperature superplasticity without grain coarsening but accompanied by large work hardening. 
Table 2 Mechanical properties attained by tensile tests of the AZ80Mg alloy plates which were fabricated by MDFing under decreasing temperature conditions to a cumulative strain of $\Sigma \Delta \varepsilon=3.2$ in advance and then warm extruded at various conditions; extrusion temperatures from $453 \mathrm{~K}$ to $523 \mathrm{~K}$ and ram strain rates from $3.0 \times 10^{-4} \mathrm{~s}^{-1}$ to $1.0 \times 10^{-2} \mathrm{~s}^{-1} . N=1$.

\begin{tabular}{|c|c|c|c|}
\hline & $\mathrm{UTS} / \mathrm{MPa}$ & Yield stress/MPa & Elongation/\% \\
\hline$\Sigma \Delta \varepsilon=3.2$ (4pass) & 346.7 & 255.7 & 15.5 \\
\hline \multicolumn{4}{|l|}{$\dot{\varepsilon}=1.0 \times 10^{-2} \mathrm{~s}^{-1}$} \\
\hline $453 \mathrm{~K}$ & 380.0 & 354.2 & 8.4 \\
\hline $473 \mathrm{~K}$ & 371.0 & 322.7 & 11.2 \\
\hline $523 \mathrm{~K}$ & 364.3 & 286.0 & 14.7 \\
\hline \multicolumn{4}{|l|}{$\dot{\varepsilon}=3.0 \times 10^{-3} \mathrm{~s}^{-1}$} \\
\hline $453 \mathrm{~K}$ & 383.5 & 353.0 & 8.9 \\
\hline $473 \mathrm{~K}$ & 375.5 & 343.4 & 7.8 \\
\hline $523 \mathrm{~K}$ & 356.0 & 310.5 & 11.6 \\
\hline \multicolumn{4}{|l|}{$\dot{\varepsilon}=1.0 \times 10^{-3} \mathrm{~s}^{-1}$} \\
\hline $453 \mathrm{~K}$ & 385.7 & 350.9 & 3.3 \\
\hline $473 \mathrm{~K}$ & 380.2 & 342.8 & 9.1 \\
\hline $523 \mathrm{~K}$ & 343.7 & 263.1 & 14.2 \\
\hline \multicolumn{4}{|l|}{$\dot{\varepsilon}=3.0 \times 10^{-4} \mathrm{~s}^{-1}$} \\
\hline $453 \mathrm{~K}$ & 366.6 & 328.3 & 12.6 \\
\hline $473 \mathrm{~K}$ & 340.9 & 306.6 & 12.2 \\
\hline $523 \mathrm{~K}$ & 324.0 & 230.1 & 17.5 \\
\hline
\end{tabular}

Table 3 Mechanical properties attained by tensile tests of the AZ80Mg alloy plates which were fabricated by MDFing under decreasing temperature conditions to $\Sigma \Delta \varepsilon=5.6$ in advance and then warm extruded at various conditions; extrusion temperatures from $453 \mathrm{~K}$ to $523 \mathrm{~K}$ and ram strain rates from $3.0 \times 10^{-4} \mathrm{~s}^{-1}$ to $1.0 \times 10^{-2} \mathrm{~s}^{-1} . N=1$.

\begin{tabular}{|c|c|c|c|}
\hline 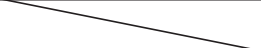 & UTS/MPa & Yield stress/MPa & Elongation $/ \%$ \\
\hline$\Sigma \Delta \varepsilon=5.6(7$ pass $)$ & 385.0 & 322.2 & 15.7 \\
\hline \multicolumn{4}{|l|}{$\dot{\varepsilon}=1.0 \times 10^{-2} \mathrm{~s}^{-1}$} \\
\hline $453 \mathrm{~K}$ & 391.0 & 336.6 & 8.1 \\
\hline $473 \mathrm{~K}$ & 371.5 & 310.1 & 11.2 \\
\hline $523 \mathrm{~K}$ & 356.8 & 280.6 & 13.6 \\
\hline \multicolumn{4}{|l|}{$\dot{\varepsilon}=3.0 \times 10^{-3} \mathrm{~s}^{-1}$} \\
\hline $453 \mathrm{~K}$ & 389.5 & 353.7 & 9.8 \\
\hline $473 \mathrm{~K}$ & 374.8 & 351.1 & 9.8 \\
\hline $523 \mathrm{~K}$ & 357.1 & 307.6 & 12.0 \\
\hline \multicolumn{4}{|l|}{$\dot{\varepsilon}=1.0 \times 10^{-3} \mathrm{~s}^{-1}$} \\
\hline $453 \mathrm{~K}$ & 383.0 & 351.6 & 8.38 \\
\hline $473 \mathrm{~K}$ & 373.1 & 347.7 & 7.5 \\
\hline $523 \mathrm{~K}$ & 371.8 & 298.3 & 10.5 \\
\hline \multicolumn{4}{|l|}{$\dot{\varepsilon}=3.0 \times 10^{-4} \mathrm{~s}^{-1}$} \\
\hline $453 \mathrm{~K}$ & 344.1 & 294.1 & 9.6 \\
\hline $473 \mathrm{~K}$ & 338.2 & 284.1 & 11.2 \\
\hline $523 \mathrm{~K}$ & 303.1 & 231.9 & 14.8 \\
\hline
\end{tabular}


Table 4 Mechanical properties attained by tensile tests of the AZ80Mg alloy plates which were fabricated by MDFing under two-step decreasing temperature conditions to $\Sigma \Delta \varepsilon=4.0$ in advance and then warm extruded at various conditions; extrusion temperatures of $453 \mathrm{~K}$ and $473 \mathrm{~K}$ and ram strain rates from $3.0 \times 10^{-4} \mathrm{~s}^{-1}$ to $1.0 \times 10^{-2} \mathrm{~s}^{-1} . N=1$.

\begin{tabular}{|c|c|c|c|}
\hline & UTS/MPa & Yield stress/MPa & Elongation/\% \\
\hline$\Sigma \Delta \varepsilon=4.0(5 \mathrm{pass})$ & 348.0 & 297.4 & 13.5 \\
\hline$\dot{\varepsilon}=1.0 \times 10^{-2} \mathrm{~s}^{-1}$ & \multicolumn{3}{|c|}{} \\
\hline $453 \mathrm{~K}$ & 385.3 & 362.3 & 8.1 \\
\hline $473 \mathrm{~K}$ & 373.2 & 330 & 10.3 \\
\hline$\dot{\varepsilon}=3.0 \times 10^{-3} \mathrm{~s}^{-1}$ & \multicolumn{3}{|c|}{} \\
\hline $453 \mathrm{~K}$ & 398.2 & 361.8 & 12.5 \\
\hline $473 \mathrm{~K}$ & 377.7 & 338.6 & 9.1 \\
\hline$\dot{\varepsilon}=3.0 \times 10^{-4} \mathrm{~s}^{-1}$ & \multicolumn{3}{|c|}{} \\
\hline $453 \mathrm{~K}$ & 375.5 & 331.8 & 13.5 \\
\hline $473 \mathrm{~K}$ & 341.3 & 277.1 & 12.5 \\
\hline
\end{tabular}

Table 5 Mechanical properties attained by tensile tests of the AZ80Mg alloy tubes which were fabricated by MDFing under decreasing temperature conditions to $\Sigma \Delta \varepsilon=5.6$ in advance and then warm extruded at the selected conditions; extrusion temperatures of $453 \mathrm{~K}$ and $473 \mathrm{~K}$ and ram strain rates of $3.0 \times 10^{-4} \mathrm{~s}^{-1}$ and $3.0 \times 10^{-3} \mathrm{~s}^{-1} . N=1$.

\begin{tabular}{|c|c|c|c|}
\hline & Peak stress $/ \mathrm{MPa}$ & Yield stress $/ \mathrm{MPa}$ & Elongation/\% \\
\hline$\Sigma \Delta \varepsilon=5.6(7 \mathrm{pass})$ & 385.0 & 322.2 & 15.7 \\
\hline$\dot{\varepsilon}=3.0 \times 10^{-3} \mathrm{~s}^{-1}$ & \multicolumn{3}{|c|}{} \\
\hline $453 \mathrm{~K}$ & 414.0 & 378.9 & 4.9 \\
\hline $473 \mathrm{~K}$ & 394.0 & 350.9 & 8.31 \\
\hline$\dot{\varepsilon}=3.0 \times 10^{-4} \mathrm{~s}^{-1}$ & \multicolumn{3}{|l}{} \\
\hline $453 \mathrm{~K}$ & 392.0 & 349.0 & 8.5 \\
\hline $473 \mathrm{~K}$ & 387.3 & 344.0 & 7.5 \\
\hline
\end{tabular}

\section{Acknowledgments}

The authors acknowledge financial supports of Grantin-Aid for Scientific Research (KAKENHI) Grant No. 20H00305 and the Light Metals Educational Foundation.

\section{REFERENCES}

1) X. Yang, H. Miura and T. Sakai: Mater. Trans. 44 (2003) 197-203.

2) Z. Li, G. Zhou, D. Li, M.K. Jain, Y. Peng and P. Wu: Int. J. Plast. 135 (2020) 102822

3) T. Al-Samman and G. Gottstein: Mater. Sci. Eng. A 490 (2008) 411420.

4) X. Yang, Z.S. Ji, H. Miura and T. Sakai: Trans. Nonferrous Met. Soc. China 19 (2009) 55-60.

5) H. Miura, K. Matsumoto and M. Kobayashi: J. Japan Inst. Met. Mater 79 (2015) 295-302.

6) H. Miura, M. Kobayashi and T. Benjanarasuth: Mater. Trans. 57 (2016) 1418-1423.

7) W. Wang, P. Han, P. Peng, H. Guo, L. Huang, K. Qiao, M. Hai, Q. Yang, H. Wang, K. Wang and L. Wang: J. Mater. Res. Technol. 9 (2020) 5252-5263.

8) H. Hosokawa and K. Higashi: Mater. Sci. Res. Inter. 6 (2000) 153-160.

9) H.K. Lin and J.C. Huang: Mater. Trans. 43 (2002) 2424-2432.

10) H. Miura, K. Minami, T. Aoba and M. Kobayashi: Procedia
Manufacturing 15 (2018) 1533-1540.

11) J. Koike, R. Ohyama, T. Kobayashi, M. Suzuki and K. Maruyama: Mater. Trans. 44 (2003) 445-451.

12) H. Miura, G. Yu and X. Yang: Mater. Sci. Eng. A 528 (2011) 69816992.

13) T. Sakai, A. Belyakov, R. Kaibyshev, H. Miura and J.J. Jonas: Prog. Mater. Sci. 60 (2014) 130-207.

14) D. Griffiths: Mater. Sci. Technol. 31 (2015) 10-24.

15) C.C. Huang, J.C. Huang, Y.K. Lin and Y.M. Hwang: Mater. Trans. 45 (2004) 3142-3149.

16) H. Miura, T. Sakai, S. Andiarwanto and J.J. Jonas: Philos. Mag. 85 (2005) 2653-2669.

17) M. Mabuchi, H. Iwasaki, K. Yanase and K. Higashi: Scr. Mater. 36 (1997) 681-686.

18) M. Mabuchi, M. Nakamura, K. Ameyama, H. Iwasaki and K. Higashi: Mater. Sci. Forum 304-306 (1999) 67-72.

19) A. Mehrabi, R. Mahmudi and H. Miura: Mater. Sci. Eng. A 765 (2019) 138274.

20) M.R. Barnett, Z. Keshavarz, A.G. Beer and D. Atwell: Acta Mater. 52 (2004) 5093-5103.

21) H. Miura and W. Nakamura: Philos. Mag. Lett. 93 (2013) 601-607.

22) J. Yoon, Y. Lee and H. Huh: J. Mech. Sci. Tech. 27 (2013) 2917-2921.

23) C.C. Huang, J.C. Huang, Y.K. Lin and Y.M. Hwang: Mater. Trans. 45 (2004) 3142-3149.

24) On the web page of The Japan Magnesium Association, http://metal. matdb.jp/magne/MG01S1100.cfm. 